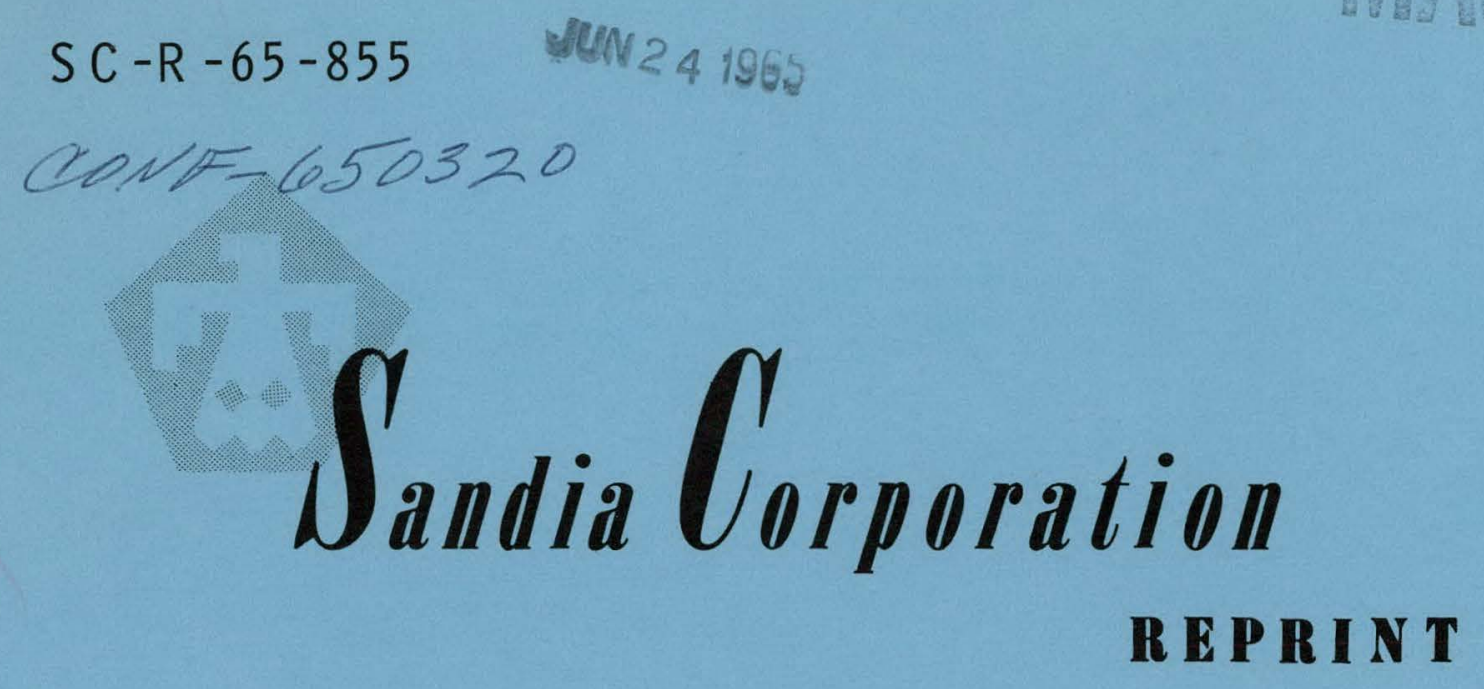

\title{
TRANSISTOR OSCILLATORS EMPLOYING PIEZOELECTRIC CERAMIC FEEDBACK NETWORKS
}

by

C E Land

MARCH 1965 


\section{DISCLAIMER}

This report was prepared as an account of work sponsored by an agency of the United States Government. Neither the United States Government nor any agency Thereof, nor any of their employees, makes any warranty, express or implied, or assumes any legal liability or responsibility for the accuracy, completeness, or usefulness of any information, apparatus, product, or process disclosed, or represents that its use would not infringe privately owned rights. Reference herein to any specific commercial product, process, or service by trade name, trademark, manufacturer, or otherwise does not necessarily constitute or imply its endorsement, recommendation, or favoring by the United States Government or any agency thereof. The views and opinions of authors expressed herein do not necessarily state or reflect those of the United States Government or any agency thereof. 


\section{DISCLAIMER}

Portions of this document may be illegible in electronic image products. Images are produced from the best available original document. 


\title{
Presented at: 1965 IEEE INTERNATIONAL CONVENTION. New York, N.Y., March 1965.
}

\author{
Issued by \\ Sandia Corporation, \\ a prime contractor to the \\ United States Atomic Energy Commission
}

\section{LEGAL NOTICE}

This report was prepared as an account of Government sponsored work. Neither the United States, nor the Commission, nor any person acting on behalf of the Commission:

A. Makes any warranty or representation, expressed or implied, with respect to the accuracy, completeness, or usefulness of the information contained in this report, or that the use of any information, apparatus, method, or process disclosed in this report may not infringe privately owned rights; or

B. Assumes any liablitities with respect to the use of, or for damages resulting from the use of any information, apparatus, method, or process disclosed in this report.

As used in the above, "person acting on behalf of the Commission" includes any employee or contractor of the Commission, or employee of such contractor. to the extent that such employee or contractor of the Commission, or employee of such contractor prepares, disseminates, or provides access to, any information pursuant to his employment or contract with the Commission, or his employment with surh sontractor. 
PAGES 1 to 50

WERE INTENTIONALLY

LEFT BLANK 


\title{
TRANSISTOR OSCILLATORS EMPLOYING PIEZOELECTRIC CERAMIC FEEDBACK NETWORKS*
}

\author{
C. E. Land \\ Sandia Laboratory \\ Albuquerque, New Mexico
}

\section{Summary}

A class of basic admittance-type oscillator circuits, each consisting of a transistor, two resistors and a ferroelectric ceramic feedback network is described. The feedback network is a ceramic bar or disk resonator having either three or four electrodes. The conventional three electrode configurations constitute two port distributed parameter networks which are used in fixed frequency oscillator's. Nuvel four electrode configurations comprising three port networks are employed to achieve variable frequency operation. The transmission characteristics for two of the three ports are strongly dependent upon the termination of the third (modulation) port. Frequency modulation is, therefore, effected by varying the termination at the modulation port. For both two-port and three-port feedback networks the transmission characteristics and, hence, the frequency determining properties depend upon the state of polarization of the ceramic under each electrode.

Matrix analysis of the complete equivalent circuit of each ceramic feedback network yields a simplified pi network distributed parameter equivalent circuit. This analytical technique is illustrated for two port resonant bar structures. A method of measuring the transmission matrix elements and using these to determine values of the lumped parameter equivalent circuit components of both bar and disk resonators is described, Finally, typical characteristics of oscillators employing both bar and disk feedback structures are included.

\section{Introduction}

Piezoelectric crystals have long been used for the control of oscillator frequencies. ${ }^{1,2,3}$ Oscillator circuits in common use employ twoterminal crystal resonators in the feedback circuits to control the frequencies of oscillation.

\footnotetext{
* This work was supported by the United
} States Atomic Energy Commission. Reproduction in whole or in part is permitted for any purpose of the U. S. Government.
This paper describes a technique of using a twoor three-port ferroelectric ceramic resonant structure as an integrated oscillator feedback network. Some of the advantages of an oscillator circuit employing this type of feedback network are:

1. The monolithic ceramic feedhark structure eliminates all lumped circuit components in the feedback network. This greatly reduces the physical size of the conventional transistor oscillator and makes completely integrated oscillator circuits entirely feasible.

2. The ceramic feedback structure is not affected by external magnetic fields, which eliminates shielding requirements.

3. The oscillator can be designed to operate near any one of the fundamental resonance modes of the feedback structure. This makes possible the design of oscillators which operate at any desired frequency in the range from one kilocycle to 100 megacycles.

4. The frequency of a given oscillator can be varied by either changing the termination at one of the feedback network ports or by switching the polarization of the ceramic in certain regions of the monolithic structure. This eliminates the necessity of changing the physical dimensions of the structure to achieve frequency trimming, and, in addition, permits frequency modulation of the oscillator by a number of simple methods.

This paper describes the basic oscillator, equivalent circuits of the feedback networks, a method of measuring the equivalent circuit components, the criteria of oscillation, and characteristics of both fixed frequency and variable frequency oscillators.

\section{Description}

Physical configurations of typical-feedback network structures are shown in Figure 1 (twoport networks) and Figure 2 (three-port networks). The arrows indicate the directions of polarization in the areas under the electrodes. In order to achieve the required $180^{\circ}$ phase shift in the 
feedback network for the fundamental contour extensional modes, the ceramic under the input electrode must be polarized in a direction opposite to that under the output electrode. The simplest oscillator circuits designed to use these feedback networks are illustrated in Figure 3 (fixed frequency oscillators) and Figure 4 (variable frequency oscillators). The frequency range for oscillators employing feedback networks of the types. shown in Figures 1 and 2 is 50 kilor cycles to 1.5 megacycles for contour extensional modes of vibration and 0.5 megacycle to 100 megacycles for thickness mode vibrators. For a given configuration of feedback structure the oscillator san be adjusted to operate near any one of the fundamental resonance frequencies. For example, using the long thin bar configurations of Figrures $1 \mathrm{~A}$ and $2 \mathrm{~A}$. the oscillator can be made to operate at a frequency corresponding to the length extensional resonance, the width extensional resoance or the thickness resonance. It was found also that the oscillator would operate at a frequensy rorresponding to the length extensional mode of the input segment, i.e., that portion of the bar covered by the input electrode.

A recent significant develupment which will assure practical designs of completely integrated oscillators capable of operating in the high frequency thickness mode of the feedback structure is illustrated in Figure 5. Newell ${ }^{4,5}$ has demionstrated that a piezoelectric resonant structure can be solidly mounted to a substrate without destroying the $Q$ of the thickness mode by isolating the resonator from the substrate by one or more quarter wavelength acoustical layers as shown in Figure 5. It is worthwhile to note that this method of mounting effectively suppresses the contour extensional modes of thin resonant structures and additionally provides stable mechanical support for the resonator. For a completely integrated oscillator, the transistor, resistors and coupling capacitor can be deposited on the same substrate as the feedback structure.

Oscillators can be designed to operate in the frequency range between one kilocycle and 50 kilocycles by using one of the split-ring configurations of feedback structure shown in Figure 6 . This type of low frequency resonant structure was described recently by Curran and Gerber. ${ }^{6 *}$

The variable frequency oscillators shown in Figure 4 can be frequency modulated by terminat-

The frequency of oscillation of a circuit using a split-ring resonator should be slightly higher than the nominal resonant frequency of the resonator. ing port 3 (see Figure 2) in a variable resistance or variable capacitance as indicated in Figures 7 and 8 , respectively. The oscillator frequency may also be varied by switching the polarization of the ceramic under the modulation electrode (port 3). ${ }^{7}$ Figure 9 illustrates the effect of varying the polarization at port 3 . The maximum frequency range available at any particular polarization state is given by the difference between the frequencies corresponding to port 3 being first open circuited (OC) and then short circuited (SC).

Although the modulation frequency ranges reported in this paper are narrow ( 1.1 percent for the bar and 2.2 percent for the disk), it shuuld be noted that thesc ranges can be increased considerably by optimizing the design of the feedback nctwork. This can be accomplished for the disk structure by alruply whlenling the insdulation ring, thereby increasing the area of ceramic under the modulation electrode (port 3). Another method by which the effective percentage frequency deviation may be increased is by use of the heterodyne, or down converter vircuit, shown in Figure 10. This scheme requires, in addition to the variable frequency oscillator, a fixed frequency oscillator and a ceramic mixer. The configuration of the mixer is similar to that illustrated in Figure $2 \mathrm{~B}$.

A practical means of frequency modulating the oscillator is to connect a transistor across the terminals of port 3 . Variations of the resistive termination of port 3 are then effected by varying the base current of the modulator transistor. A voltage variable capacitor may be $\mathrm{cm}$ ployed in a similar manner to vary the capacitive termination at port 3 and, hence, produce frequency modulation.

\section{Theory}

A matrix approach to the analysis of feedback nscillators has been described by Cote. 8,9 This method of analysis is used here to derive expressions which describe the conditions which must be satisfied by the circuits of Figures 3 and 4 before oscillation can occur. The criteria for oscillation and the oscillator frequency are then expressed in terms of the transistor parameters and the small-signal response characteristics of the ceramic feedback network.

The transistor oscillator circuits of Figures 3 and 4 can each be represented, neglecting the modulation port of the feedback network, the base bias resistor $R_{B}$, and the output coupling capacitor, by the generalized block diagram shown in Figure 11. Figure 11 shows the oscillator represented by a two-port network with input and output 
ports open circuited. The oscillator two-port consists of two parallel connected two-ports, one containing the active element and the other the passive feedback network. The oscillator twoport is described by the following equation

$$
\left[\begin{array}{l}
I_{1} \\
I_{2}
\end{array}\right]=\left[\begin{array}{ll}
Y_{11} & Y_{12} \\
Y_{21} & Y_{22}
\end{array}\right]\left[\begin{array}{l}
V_{1} \\
V_{2}
\end{array}\right]
$$

where $Y_{i j}=y_{A i j}+y_{F i j},\left[y_{A}\right]$ is the admittance matrix of the active (transistor) two-port and $\left[\mathrm{y}_{\mathbf{F}}\right]$ is the admittance matrix of the passive feedback two-port. Since the ceramic feedback networks are both passive and reciprocal, they can be represented by an admittance matrix of the form

$$
\left[\mathrm{y}_{\mathrm{F}}\right]-\left[\begin{array}{ll}
\mathrm{y}_{11} & \mathrm{y}_{12} \\
\mathrm{y}_{21} & \mathrm{y}_{22}
\end{array}\right]
$$

The transistor can be represented by an admittance matrix in terms of its $h$ parameters ${ }^{14}$ as follows

$$
\left[\mathrm{y}_{A}\right]=\left[\begin{array}{ll}
\frac{1}{\mathrm{~h}_{11}} & \frac{-h_{12}}{\mathrm{~h}_{11}} \\
\frac{h_{21}}{\mathrm{~h}_{11}} & \frac{|\mathrm{h}|}{\mathrm{h}_{11}}
\end{array}\right]
$$

where $|\mathrm{h}|=\mathrm{h}_{11} \mathrm{~h}_{22}-\mathrm{h}_{12} \mathrm{~h}_{21}$.

For the purpose of this analysis, the transistor is considered to be unilateral, i.e., $\mathrm{h}_{12}=0$, then the matrix becomes

$$
\left[\mathrm{y}_{A}\right]=\left[\begin{array}{cc}
\frac{1}{h_{11}} & 0 \\
\frac{h_{21}}{h_{11}} & h_{22}
\end{array}\right]=\left[\begin{array}{ll}
\frac{1}{h_{\text {ie }}} & 0 \\
\frac{h_{f e}}{h_{\text {ie }}} & h_{\text {oe }}
\end{array}\right]
$$

In equation ( 1 ) the quantities $I_{1}$ and $I_{2}$ are current generators driving the oscillator twoport. In a stable circuit the values of $V_{1}$ and $V_{2}$ would be zero if $I_{1}$ and $I_{2}$ were zero. However, in an oscillator $V_{1}$ and $V_{2}$ exist without the presence of driving generators, hence $I_{1}$ and $I_{2}$ are simply replaced by their internal admittances, which are zern, for the purpose of this analysis. In order to obtain a nontrivial solution for $V_{1}$ and $V_{2}$ with $I_{1}$ and $I_{2}$ equal to zero, the determinant of the admittance matrix must be identically zero, i.e.

$$
\left|\begin{array}{cc}
Y_{11} & Y_{12} \\
Y_{21} & Y_{22}
\end{array}\right| \equiv 0
$$

Although the matrix elements of the transistor network are considered to be real, the matrix elements of the feedback network must be predominantly imaginary, thus making the oscillator matrix elements complex.

$$
Y_{i j}=G_{i j}+j B_{i j}
$$

Equation (5) can be rewritten as

$$
\left[\begin{array}{ll}
G_{11}+j B_{11} & G_{12}+j B_{12} \\
G_{21}+j B_{21} & G_{22}+j B_{22}
\end{array}\right] \equiv 0
$$

or

$$
\begin{aligned}
& \left(G_{11}+j B_{11}\right)\left(G_{22}+j B_{22}\right)- \\
& -\left(G_{12}+j B_{12}\right)\left(G_{21}+j B_{21}\right) \equiv 0
\end{aligned}
$$

Both the real and imaginary terms of (8) must be equal to zero, hence

$$
\begin{aligned}
& \left(G_{11} G_{22}-G_{12} G_{21}\right) \\
& -\left(B_{11} B_{22}-B_{12} B_{21}\right)=0
\end{aligned}
$$

and

$$
\begin{aligned}
& \left(G_{11} B_{22}+G_{22} B_{11}\right) \\
& -\left(G_{12} B_{21}+G_{21} B_{12}\right)=0
\end{aligned}
$$

Equations (9) and (10) determine the conditions for oscillation and the oscillator frequencies for admittance-type oscillators.

Since the ceramic feedback networks are both passive and reciprocal, they may be represented by the general pi network equivalent circuit of Figure 12. The admittance matrix for the pi network is given by

$$
\left[y_{F}\right]=\left[\begin{array}{ll}
\dot{Y}_{1}+Y_{3} & -Y_{3} \\
-Y_{3} & Y_{2}+Y_{3}
\end{array}\right]
$$

The equivalent circuit parameters $Y_{1}, Y_{2}$, and $\mathrm{Y}_{3}$ can be evaluated by a lengthy derivation making use of the dielectric, elastic and piezoelectric properties of the material, and the feedback structure geometry. ${ }^{10}$ This technique is illustrated for the symmetrical two-port bar in Appendix $A, Y_{1}, Y_{2}$, and $Y_{3}$ can also be evaluated by measuring open circuit and short circuit impedances $11,12,13$ or admittances at the input and output ports of the feedback network. A method for evaluating the equivalent circuit parameters using admittance measurements is derived in Appendix $B$.

When the feedback network is represented by the equivalent circuit of Figure 12, it can be 
shown ${ }^{8,9}$ that a necessary condition for oscillation is that the susceptive component of $\mathrm{Y}_{3}$ must be opposite in sign to the susceptive components of $\mathrm{Y}_{1}$ and $\mathrm{Y}_{2}$. It can also be shown ${ }^{9}$ that oscillation occurs near the frequency at which

$$
\left|B_{3}\right|=\left|B_{1} \oplus B_{2}\right|=\left|\frac{B_{3} B_{2}}{B_{1}+B_{2}}\right| \text {, }
$$

where $Y_{i}=G_{i}+j B_{i}$.

In other words, oscillation occurs near the frequency where the susceptive component of $\mathrm{Y}_{3}$ is parallel resonant with the susceptive component of the series combination of $Y_{1}$ and $Y_{2}$. This has been verified by measurements on all four types of feedback structures shown in Figures 1 and 2.

A characteristic common to all of the feedback structures shown in Figures 1 and 2 is that both $Y_{1}$ and $Y_{2}$ are predominantly capacitive. The predominant capacitive component of $\mathrm{Y}_{1}$ and $\mathrm{Y}_{2}$ is generally designated $\mathrm{C}_{0 i}$, where $\mathrm{i}$ is 1 or 2 , and it is defined, for the configurations in Figures 1 and 2 , as

$$
C_{o i}=\operatorname{Re}\left[\epsilon_{33}^{T}\left(1-k_{m}^{2}\right)\right]\left(\frac{a i}{t}\right),
$$

where $\epsilon_{33}^{T}$ is the free dielectric constant of the ceramic, $\mathrm{k}_{\mathrm{m}}$ is the resonance mode electromechanical coupling factor, and $a i / t$ is the ratio of the $i^{\text {th }}$ electrode area to the thickness $t$ of the ceramic. Since $Y_{1}$ and $Y_{2}$ are capacitive, $Y_{3}$ must be inductive at the oscillator frequency. Therefore, the oscillator frequency is always higher than the series resonance of the $L$ and C' oomponent.s of $\mathrm{Y}_{3}$ (see Figure 18). Since these observations are true, in general, for all feedback network configurations, it may be concluded that, at the oscillator frequency, the ceramic feedback network can always be represented by the simplified equivalent circuit of Figure 19 (neglecting losses). In Figure 19,

$$
\mathrm{n}=\frac{\mathrm{Y}_{2}}{\mathrm{Y}_{1}} \cong \frac{\mathrm{C}_{02}}{\mathrm{C}_{01}}=\frac{\mathrm{a}_{2}}{\mathrm{a}_{1}}
$$

The equivalent circuit in Figure 19 is precisely the conventional lumped component feedback network of the Colpitts oscillator. A detailed analysis of this oscillator is given in Reference 14. The most significant results of Zelinger's paper ${ }^{14}$ are the derivations of an expression for the oscillator frequency $\omega$ and an expression for the limiting magnitude of $\beta\left(=h_{f e}\right)$ of the transistor for sustained oscillations. These are, respectively,

$$
\omega \doteq \sqrt{\frac{\mathrm{n}+1}{\mathrm{LCn}}}
$$

and

$$
\beta=h_{\text {fe }} \geqq \operatorname{nh}_{\text {ie }}\left(h_{\text {oe }}+\frac{1}{R_{L}}\right)
$$

If more general expressions for oscillator frequency and $\beta$ are required, we must refer back to equations (9) and (10). Assuming the feedback network matrix of equation (11), we. can write

$$
\begin{aligned}
Y_{1}+Y_{3}=y_{1 s c} & =g_{1 s c}+j b_{1 s c} \\
Y_{2}+Y_{3}=y_{2 s c} & =g_{2 s c}+j b_{2 s c} \\
Y_{3} & =G_{3}+j B_{3}
\end{aligned}
$$

Making uss of the relationships of equations (4) and (17), the admittance matrix elements of equation (1) are

$$
\begin{aligned}
& Y_{11}=\frac{1}{h_{i e}}+g_{1 s c}+j b_{1 s c} \\
& Y_{22}=g_{0}+g_{2 s c}+j b_{2 s c} \\
& Y_{12}=-Y_{3}=-r_{3}-j B_{3} \\
& Y_{21}=\frac{h_{\text {fe }}}{h_{\text {i.e }}}-G_{3}-j B_{3}
\end{aligned}
$$

Substituting (18) through (21) into equation (9), we obtain

$$
\begin{aligned}
b_{1 s c} b_{2 s c}-B_{3}^{2}= & \frac{1}{h_{i e}}\left(g_{o}+g_{2 s c}+G_{3} h_{f e}\right) \\
& +g_{1 s c}\left(g_{o}+g_{2 s c}\right)-G_{3}^{2}
\end{aligned}
$$

This equation can be solved for $\omega$.

Substituting (18) through (21) into equation (10), we oltain an cxpression for $\beta$

$$
\begin{aligned}
\beta=h_{\mathrm{fe}}=\frac{h_{\text {iee }}}{B_{3}} & {\left[2 G_{3} B_{3}-b_{2 s c}\left(\frac{1}{h_{i e}}+g_{1 s c}\right)\right.} \\
& \left.-b_{1 s c}\left(g_{o}+g_{2 s c}\right)\right]
\end{aligned}
$$

In equations (18), (22) and (23),

$$
g_{0}=h_{\text {oe }}+G_{L} \text {, and } G_{L}=1 / R_{L} \text {. }
$$

\section{Measurements}

Two types of measurements were made for this study. They are:

1. Measurement of the open-circuit and short-circuit admittances at the input and output ports of each configuration of ceramic feedback structure in Figures 1 and 2. 
2. Measurement of oscillator frequencies using each of the feedback structures of Figures 1 and 2 .

The material used in the fabrication of the feedback structures was the lead zirconate titanate ceramic, $\mathrm{Pb} .{ }_{99} \mathrm{Bi} .02\left(\mathrm{Zr} .65 \mathrm{Ti} .{ }_{35}\right){ }_{.98} \mathrm{O}_{3}$, hot pressed at $1300^{\circ} \mathrm{C}$ for one hour at 3000 pounds per square inch pressure. The dimensions of the feedback structures used are given in Table I.

\section{TABLE I}

\begin{tabular}{|c|c|c|c|}
\hline $\begin{array}{c}\text { Configuration } \\
\text { Figure } \\
\end{array}$ & $\begin{array}{c}\text { Length or } \\
\text { Diameter } \\
\text { (inches) }\end{array}$ & $\begin{array}{c}\text { Width } \\
\text { (inches) }\end{array}$ & $\begin{array}{l}\text { Thickness } \\
\text { (inches) } \\
\end{array}$ \\
\hline $1 \mathrm{~A}$ & 0.320 & 0.050 & 0.006 \\
\hline $1 \mathrm{~B}$ & 0.250 & & 0.003 \\
\hline $2 \mathrm{~A}$ & 0.335 & 0.60 & 0.006 \\
\hline $2 \mathrm{~B}$ & 0.250 & & 0.003 \\
\hline
\end{tabular}

The electrodes of Figure $1 \mathrm{~A}$ are equal in length with 0.010 -inch separation between them. The electrodes of Figure $2 \mathrm{~A}$ are equal in length ( 0.105 inch) with 0.010 -inch separation between them. The dot electrode of Figure $1 B$ is 0.090 inch diameter, and the ring is 0.050 inch wide with 0.010 -inch space between the dot and the ring. The dot electrode of Figure $2 \mathrm{~B}$ is 0.050 inch in diameter, the modulator ring and the outside ring are each 0.030 wide, and there is 0.010 inch spacing between the dot and modulator ring and, also, between the modulator and outside rings.

The admittance measurements in (1) above were made using an Alford Bridge as described in Reference 7. The results of these measurements were used to calculate the pi network equivalent circuit parameters using the relationships derived in Appendix B. The small-signal characteristics of the feedback structures are, perhaps, best presented in this manner.

All oscillator frequency measurements were made using the same oscillator circuit components, with the exception of the feedback networks. In this circuit $R_{L}=5.6 \mathrm{~K}, R_{B}=820 \mathrm{~K}$, and $V_{C E}=6$ volts. The transistor used was a Type 2N718A with the following parameters measured at 50 kilocycles:

$$
\begin{aligned}
& h_{\text {ie }}=30,000 \text { ohms } \\
& h_{\text {re }}=625 \times 10^{-6} \\
& h_{\text {fe }}=46 \\
& h_{\text {oe }}=5.6 \text { micromho }
\end{aligned}
$$

These parameters were measured using a Baird-Atomic Transistor Test Set, Model GS-3.

\section{Results and Discussion}

The small-signal characteristics of the twoport bar and disk structures were measured as frequency was varied in the vicinity of the oscillator frequency. These measurements were repeated for different values of polarization of the ceramic under the input electrode for each structure. A typical set of results for the two-port bar structure is given in Figure 20. The oscillator frequencies are indicated for each of the polarization values. It is interesting that, although the equivalent circuit admittances are quite sensitive to polarization near the resonant frequency of $\mathrm{Y}_{3}$, they are almost completely insensitive to polarization state at the oscillator frequency. It is easily seen from these curves that, at the oscillator frequency, $\mathrm{Y}_{1}$ and $\mathrm{Y}_{2}$ are almost purely capacitive and $\mathrm{Y}_{3}$ is nearly a pure inductance. This confirms the approximate equivalent circuit of Figure 19. Since the frequencies in the neighborhood of $\mathrm{Y}_{3}$ resonance are of no interest in the analysis of the operation of the oscillator, the pi-network equivalent circuit parameters are plotted at the oscillator frequencies only for the two-port disk (Figure 21). Here again $Y_{1}$ and $Y_{2}$ are capacitive and $Y_{3}$ is inductive.

Oscillator frequency was measured as a function of resistive and capacitive termination at port 3 with both the bar and disk feedback structures. The results are plotted as percentage frequency deviation versus resistive termination in Figure 7, and versus capacitive termination in Figure 8. Similar measurements of oscillator frequency were made as polarization under the modulation electrode (port 3) was varied. The resultant oscillator frequency deviations with port 3 open-circuited and short-circuited are shown for both the bar and disk structures in Figure 9. Figures 7,8 , and 9 show that the frequency deviation produced using the disk structure is about twice that obtained with the bar. For this reason, it was decided to measure the variation of the disk structure $Y_{1}, Y_{2}$, and $Y_{3}$ parameters at the oscillator frequency for each of the modulation conditions and polarizations given in Figures 7, 8, and 9. The pi-network equivalent circuit parameters are plotted as functions of resistive termination at port 3 in Figure 22; they are plotted as functions of capacitive termination at port 3 in Figure 23; and these parameters are shown as functions of polarization at port 3 in Figure 24. In each case, $Y_{1}$ and $Y_{3}$ remain essentially constant at the oscillator frequency, 
whereas $\mathrm{Y}_{2}$ exhibits nominal variation throughout the range of frequency deviation.

For each feedback network configuration studied, the oscillator operated at a frequency slightly above one of the fundamental resonances of the feedback structure. In each instance, $Y_{1}$ and $\mathrm{Y}_{2}$ are capacitive and $\mathrm{Y}_{3}$ is inductive at the oscillator frequency. This gives the same feedback network configuration as the standard Colpitts oscillator.

\section{Applications}

Although no attempt has been made in this paper to discuss such matters as temperature stabilization of the oscillator circuits described, it is felt that standard design procedures can be used to solve these problems." This paper does accomplish an introduction to techniques which will lead to completely integrated oscillator circuit design.

Although large frequency shifts are not accomplished by varying the termination or polarization of the modulation segment of the three port networks, simple down-conversion techniques, such as the one illustrated in Figure 10 , provide a considerable range of frequency deviation for a system. Such techniques could be employed in the design of integrated subcarrier oscillator systems for FM-FM telemetry channels. Other possible applications include frequency shift communication channels and beat frequency oscillators in transistorized communications receivers.

\section{Acknowledgment}

The author wishes to thank Messrs. 1. $\mathrm{D}$. McKinney and L. M. Parker for their invaluable assistance in measurements and data reduction.

\section{Appendix A}

Equivalent Circuit Analysis of a

Piezoelectric Ceramic Two-Port Network (Long Thin Bar Structure)

The purpose of this Appendix is to illustrate the derivation of the pi network equivalent circuit of the structure of Figure 1A.

The equivalent circuit of a long thin bar resonator with one end clamped and one end free is given by Katz ${ }^{15}$ and Berlincourt, et al. ${ }^{1}$ and shown in Figure 13. In Figure 13,

$$
\begin{aligned}
Y_{0}^{\prime} & =G_{0}+p C_{0}=\frac{p w \ell}{t_{1}} \epsilon_{33}^{T}\left(1-k_{m}^{2}\right) \\
p & =j \omega
\end{aligned}
$$

$w, \ell, t,=$ width, length and thickness, respectively, of the bar resonator

$\epsilon_{33}^{\mathrm{T}}=$ free dielectric constant

$\mathrm{k}_{\mathrm{m}}=$ effective electromechanical coupling factor

$$
=\sqrt{8 / \pi^{2}} \mathrm{k}_{31}=\sqrt{8 / \pi^{2}} \mathrm{~d}_{31} / \sqrt{\epsilon_{33}^{\mathrm{T}} \mathrm{s}_{11}^{\mathrm{E}}}
$$$$
\phi=\frac{w d_{31}}{s_{11}^{E}}
$$

$z=\frac{w t}{s_{11}^{E} v}$, the mechanical characteristic impedanee

$$
\begin{aligned}
v^{E} & =1 / \sqrt{\rho s_{11}^{E}}, \text { elastic wave phase velocity } \\
\gamma & =p \sqrt{\rho s_{11}^{E}}=\frac{p}{v^{E}}=\alpha+j \beta \text {, elastic wave }
\end{aligned}
$$

propagation constant

Using the Norton transformation illustrated in Figure 14, the circuit of Figure 15 becomes equivalent to that shown in Figure 13. In Figure 15 ,

$$
\begin{aligned}
& z_{a}=2 z \operatorname{coth} \frac{\gamma \ell}{2}=-j 2 z \cot \frac{\omega \ell}{v} \\
& z_{b}=2 z \tanh \frac{\gamma \ell}{2}=j 2 z \tan \frac{\omega \ell}{v}
\end{aligned}
$$

The transmission equation for the equivalent circuit of Figure 15 is given by

$$
\begin{aligned}
{\left[\begin{array}{l}
V \\
I
\end{array}\right] } & =\left[\begin{array}{l}
A_{1}
\end{array}\right]\left[\begin{array}{l}
A_{2} \\
A_{3}
\end{array}\right]\left[\begin{array}{l}
F \\
u
\end{array}\right] \\
& =\left[\begin{array}{ll}
1 & 0 \\
Y_{0} & 1
\end{array}\right]\left[\begin{array}{ll}
\frac{\phi}{2} & 0 \\
0 & 2 \phi
\end{array}\right] \cdot\left[\begin{array}{ll}
\frac{Z_{a}+Z_{b}}{Z_{b}} & Z_{a} \\
\frac{1}{Z_{b}} & 1
\end{array}\right]\left[\begin{array}{l}
F \\
u
\end{array}\right] \\
& =\left[\begin{array}{ll}
\frac{Z_{a}+Z_{b}}{2 \phi Z_{b}} & \frac{Z_{a}}{2 \phi} \\
Y_{0}\left(Z_{a}+Z_{b}\right)+4 \phi^{2} & \frac{Y_{0} Z_{a}+4 \phi}{2 \phi} \\
\frac{2 \phi}{2}
\end{array}\right]\left[\begin{array}{l}
F \\
u
\end{array}\right]
\end{aligned}
$$

where $F$ is the force and $u$ is the particle veloc- . ity at the mechanical terminals. 
The elements of the transmission matrix of equation (A1) are given by

$$
\begin{aligned}
& a_{11}=\frac{Z_{a}+Z_{b}}{2 \phi Z_{b}} ; \quad a_{12}=\frac{Z_{a}}{2 \phi} \\
& a_{21}=\frac{Y_{0}\left(Z_{a}+Z_{b}\right)+4 \phi^{2}}{2 \phi Z_{b}} \\
& a_{22}=\frac{Y_{0} Z_{a}+4 \phi^{2}}{2 \phi}
\end{aligned}
$$

We may now consider the structure of Figure $1 \mathrm{~A}$ to be composed of two bar resonators, each of length $\boldsymbol{L}$, interconnected mechanically. The equivalent circuit of the left half segment of Figure 1A is the circuil shuwn in Figure 15, excepl for the termination at the mechanical terminals. The equivalent circuit of the right half segment of the bar of Figure $1 \mathrm{~A}$ is precisely the reverse of Figure 15 because of symmetry. From equations (A1) and (A2) the transmission matrix of the left half segment is

$$
[A]=\left[\begin{array}{ll}
a_{11} & a_{12} \\
a_{21} & a_{22}
\end{array}\right]
$$

Then, since the complete network is passive and reciprocal, the transmission matrix for the right half segment of Figure $1 \mathrm{~A}$ is the matrix of the reverse quadrupole $e^{16}$

$$
[R]=\left[\begin{array}{ll}
a_{22} & a_{12} \\
a_{21} & a_{11}
\end{array}\right]
$$

The equivalent circuit of the complete symmetrical two segment bar of Figure $1 \mathrm{~A}$ is that shown in Figure 16. The transmission equation de-1 scribing this equivalent circuit is

$$
\begin{aligned}
{\left[\begin{array}{l}
V_{1} \\
I_{1}
\end{array}\right] } & =[A]\left[\begin{array}{l}
R \\
A
\end{array}\right]\left[\begin{array}{l}
V_{2} \\
I_{2}
\end{array}\right] \\
& =\left[\begin{array}{ll}
a_{11} a_{22}+a_{12} a_{21} & 2 a_{11} a_{12} \cdot \\
2 a_{21} a_{22} & a_{11} a_{22}+a_{12} a_{21}
\end{array}\right]\left[\begin{array}{l}
V_{2} \\
I_{2}
\end{array}\right] \\
& =\left[\begin{array}{ll}
A_{11} & A_{12} \\
A_{21} & A_{11}
\end{array}\right]\left[\begin{array}{l}
V_{2} \\
I_{2}
\end{array}\right] .
\end{aligned}
$$

The admittance matrix of the structure, Figure $1 \mathrm{~A}$, is ${ }^{27}$.

$$
[\mathrm{Y}]=\left[\begin{array}{cc}
\frac{A_{11}}{A_{12}} & -\frac{|A|}{A_{12}} \\
\frac{-1}{A_{12}} & \frac{A_{11}}{A_{12}}
\end{array}\right]=\left[\begin{array}{ll}
y_{11} & y_{12} \\
y_{21} & y_{22}
\end{array}\right]
$$

Since the network is passive and reciprocal $|A|=1$. Equations $(A 6)$ apply to the pi equivalent network of Figure 12, where

$$
\begin{aligned}
& Y_{1}=y_{11}+y_{12}=\frac{A_{11}}{A_{12}}-\frac{1}{A_{12}} \\
& Y_{2}=Y_{1} \\
& Y_{3}=-y_{12}=\frac{1}{A_{12}}
\end{aligned}
$$

Substituting (A2) into (A5) and (A5) into (A6) we obtain

$$
\begin{aligned}
& Y_{1}=Y_{2}=Y_{0}+\frac{j \phi^{2}}{z} \tan \frac{\omega \ell}{v^{E}} \\
& Y_{3}=\frac{-j \phi^{2}}{2} \tan ^{2} \frac{\omega \ell}{2 v^{E}} \tan \frac{\omega \ell}{v^{E}}
\end{aligned}
$$

Equations (A10) and (A11) describe the distributed parameter equivalent circuit of Figure 17. In Figure 17,

$$
\begin{aligned}
& \mathrm{Y}_{\mathrm{a}}=\frac{j}{4 \mathrm{z}} \tan \frac{\omega \ell}{\mathrm{v}} \\
& \mathrm{Y}_{\mathrm{b}}=\frac{-\mathrm{j}}{8 \mathrm{z}} \tan ^{2} \frac{\omega \ell}{2 \mathrm{v}} \tan \frac{\omega \ell}{\mathrm{v}^{\mathrm{E}}}
\end{aligned}
$$

The polarities indicated on the ideal transformers correspond to opposite polarizations under the two electrodes. This is required in order to obtain $180^{\circ}$ phase shift through the network.

The resonances of $Y_{1}\left(=Y_{2}\right)$ and $Y_{2}$ occur at

$$
\omega=\frac{n \pi v^{E}}{2 \ell} \quad n=1,3,5, \ldots
$$

The antiresonances of $\mathrm{Y}_{1}\left(=\mathrm{Y}_{2}\right)$ and $\mathrm{Y}_{\mathrm{a}}$ ' occur at

$$
\omega=\frac{\mathrm{n} \pi \mathrm{v}^{\mathrm{E}}}{\ell} \quad \mathrm{n}=0,1,2,3, \ldots
$$

Similarly, the resonance frequencies of $Y_{3}$ and $\dot{Y}_{b}$ occur at the values given by (A14) and the antiresonances occur at the values given by (A15).

A lumped parameter equivalent of the circuit in Figure 17 is given in Figure 18. 


\section{Appendix B}

Measurement of the Pi Network Equivalent Circuit Parameters of a Piezoelectric Ceramic Two-Port Network

The purpose of this Appendix is to derive a method of measuring the pi network equivalent circuit parameters of a two-port piezoelectric structure using open circuit and short circuit admittances. This measurement technique also yields the transmission matrix elements, ${ }^{12}$ the admittance matrix elements, the image impedances and the complex image transfer constant. ${ }^{13}$

The pi equivalent circuit of the two-port network is given in Figure 12 . 'l'he admittance matrix for this network is given by

$$
\begin{aligned}
{[Y] } & \equiv\left[\begin{array}{ll}
y_{11} & y_{12} \\
y_{21} & y_{22}
\end{array}\right]=\left[\begin{array}{cc}
Y_{1}+Y_{3} & -Y_{3} \\
-Y_{3} & Y_{2}+Y_{3}
\end{array}\right] \\
& =\left[\begin{array}{ll}
\frac{a_{22}}{a_{12}} & \frac{-|A|}{a_{12}} \\
\frac{-1}{a_{12}} & \frac{a_{11}}{a_{12}}
\end{array}\right]
\end{aligned}
$$

Short circuit admittance measurements at ports 1 and 2 , respectively, give

$$
\begin{aligned}
& y_{15 c}=\left.\frac{I_{1}}{V_{1}}\right|_{\text {port 2 sc }}=Y_{1}+Y_{3}=\frac{a_{22}}{a_{12}}=y_{11} \\
& y_{2 s c}=\left.\frac{I_{2}}{V_{2}}\right|_{\text {port 1 sc }}=Y_{2}+Y_{3}=\frac{a_{11}}{a_{12}}=y_{22}
\end{aligned}
$$

These measurements yield the necessary information to synthesize the pi equivalent network with the exception of evaluating $Y_{3}$. Open circuit admittance measurements at ports 1 and 2 , respectively, yield

$$
\begin{aligned}
& y_{10 \mathrm{c}}=\left.\frac{I_{1}}{V_{1}}\right|_{\text {port 2 oc }}=Y_{1}+\left(Y_{2} \oplus Y_{3}\right)=\frac{a_{21}}{a_{11}}=\frac{1}{Z_{11}} \\
& y_{20 c}=\left.\frac{I_{2}}{V_{2}}\right|_{\text {port 1 oc }}=Y_{2}+\left(Y_{1} \oplus Y_{3}\right)=\frac{a_{21}}{a_{22}}=\frac{1}{Z_{22}}
\end{aligned}
$$

Noting that $|A|=a_{11} a_{22}-a_{12} a_{21}=1$ for a passive reciprocal network, and, from equation (B1) $Y_{3}=1 / a_{12}$, we can now evaluate $Y_{3}$ as follows.

$$
\begin{aligned}
|A| & =a_{11} a_{22}-a_{12} a_{21}=a_{12}^{2}\left(y_{1 s c} y_{2 s c}\right)-a_{12}^{2}\left(\dot{y}_{1 s c} y_{2 o c}\right) \\
& =a_{12}^{2}\left(y_{1 s c} y_{2 s c}\right)-a_{12}^{2}\left(y_{2 s c} y_{10 c}\right)=1
\end{aligned}
$$

Rewriting (B6) we obtain

$$
\begin{aligned}
& a_{12}^{2}\left(\frac{a_{22} a_{11}}{a_{12}^{2}}-\frac{a_{22} a_{21}}{a_{12} a_{22}}\right)=1 \\
& a_{12}^{2}\left(\frac{a_{22} a_{11}}{a_{12}^{2}} \frac{a_{11} a_{21}}{a_{12} a_{11}}\right)=1
\end{aligned}
$$

or

$$
\begin{aligned}
\frac{1}{a_{12}^{2}} & =\left(y_{1 s c} y_{2 s c}=y_{1 s c} y_{2 v i}\right) \\
& =\left(y_{1 s c} y_{2 s c}-y_{2 s c} y_{l o c}\right)=y_{3}^{2}
\end{aligned}
$$

Hence;

$$
\begin{aligned}
Y_{3} & =\left(y_{1 s c} y_{2 s c}-y_{1 s c} y_{2 o c}\right)^{1 / 2} \\
& =\left(y_{1 s c} y_{2 s c}-y_{2 s c} y_{1 o c}\right)^{1 / 2}
\end{aligned}
$$

Therefore, from (B1) and (B2),

$$
\begin{aligned}
& \mathrm{Y}_{1}=\mathrm{y}_{1 \mathrm{sc}}-\mathrm{Y}_{3} \\
& \mathrm{Y}_{2}=\mathrm{y}_{2 \mathrm{sc}}-\mathrm{Y}_{3}
\end{aligned}
$$

The transmission matrix elements are given by:

$$
\begin{array}{ll}
a_{11}=\frac{y_{2 s c}}{Y_{3}} & d_{21}=Y_{1}+Y_{2}+\frac{Y_{1} Y_{2}}{Y_{3}} \\
a_{12}=\frac{1}{Y_{3}} & a_{22}=\frac{Y_{1 s c}}{Y_{3}} .
\end{array}
$$

The image transfer constant $\theta$ is given by

$$
\begin{aligned}
\theta & =\ln \left[\left(\mathrm{a}_{11} \mathrm{a}_{22}\right)^{1 / 2}+\left(\mathrm{a}_{12} \mathrm{a}_{21}\right)^{1 / 2}\right] \\
\theta & =\ln \left[\frac{\left(\mathrm{y}_{1 s c} \mathrm{y}_{2 s c}\right)^{1 / 2}+\left(\mathrm{y}_{1 s c} \mathrm{y}_{2 o c}\right)^{1 / 2}}{\left(\mathrm{y}_{1 s c} \mathrm{y}_{2 s c}-\mathrm{y}_{1 s c} \mathrm{y}_{2 o c}\right)^{1 / 2}}\right] \\
& =\ln \left(\mathrm{re}^{j \phi}\right)=\ell \mathrm{nr}+j \phi \\
& =\alpha+j \beta
\end{aligned}
$$




\section{References}

1. D. Berlincourt, D. R. Curran, and H. Jaffe, "Physical Acoustics," W. P. Mason, Ed., Academic Press, New York, N.Y., vol. 1, Part A, pp. 393-398, 1964 .

2. W. P. Mason, "Electromechanical Transducers and Wave Filters," Van Nostrand Co., Inc., Princeton, New Jersey, 1942.

3. W. P. Mason, "Piezoelectric Crystals and Their Applications to Ultrasonics, "Van Nostrand Co., Inc., Princeton, New Jersey, 1950.

4. W. E. Newell, "A New Piezoelectric Tuner for Integrated Circuits, "1964 Symposium on Sonics and Ultrasonics, "Oct. 14, 15, 16, Santa Monica, California.

5. W. E. Newell, "Tuned Integrated Circuits A State-of-the-Art Survey, "Proc. IEEE, Vol. 52, pp. 1603-1608, Dec. 1964.

6. D. R. Curran and W. J. Gerber, "LowFrequency Ceramic Band-Pass Filters, "Proc. 1963 Electronic Components Conference, Washington, D. C.

7. C. E. Land; G. W. Smith, and C. R. Westgate, "The Dependence of the Small-Signal Parameters of Ferroelectric Ceramic Resonators Upuii Stalte of Fularizaliun, "IEEE Trans. Un Sonics and Ultrasonics, vol. SU-11, pp. 8-19, June 1964.

8. A. J. Cote, Jr., "Matrix Analysis of Oscillators and Transistor Applications, "IRE Trans. on Circuit Theory, vol. CT-5, pp. 181-188, Sept. 1958.
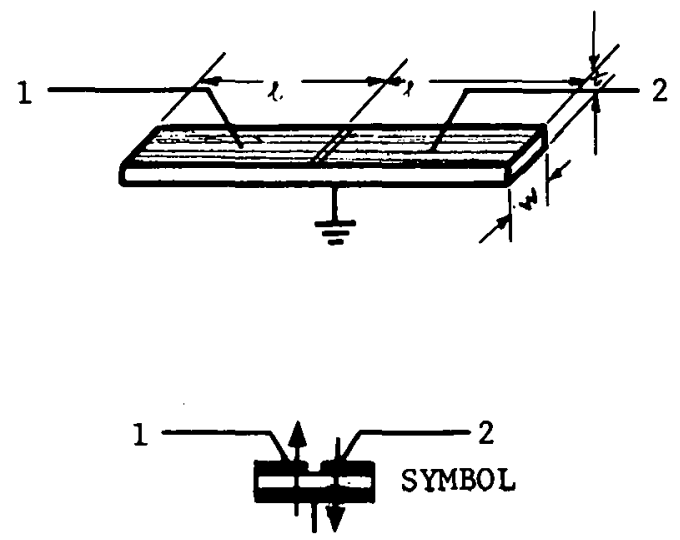

FIGURE 1A
9. A. J. Cote, Jr. and J. B. Oakes, "Linear Vacuum Tube and Transistor Circuits, "McGrawHill Co., Inc., New York, N.Y. Ch. 9, 1961.

10. B. van der Veen, "The Equivalent Network of a Piezoelectric Crystal with Divided Electrodes," Phillips Research Report, vol. 11, pp. 66-79.

11. A. Lungo and F. Sauerland, A Ceramic Band Pass Transfilter and Filter Element, "Clevite Piezoelectric Division, Bedford, Ohio, Technical Paper TP-46.

12. W. R. Hinton, "The Measurement of " $A$ " Matrix Elements of Passive Networks, "Electronic Engng., vol. 25, pp. 151-152, April 1953.

13. H. P. Biggar, "Transfer Matrix of a Four Terminal Passive Network in Terms of Its Image Parameters, " Electronic Engng., vol. 25, pp. 152-153, April 1953.

14. G. Zelinger, "Matrix Analysis of the Colpitts Oscillator, "' Electronic Engng., vol. 36, pp. 394-398, June 1964 .

15. H. W. Katz, Ed., "Solid State Magnetic and Dielectric Devices, "John Wiley and Sons, Inc., New York, N.Y., Ch. 3, 1959.

16. M. E. Fislier', "Tlıe Malıix Appruach lo Filters and Transmission Lines, "Electronic Engng., vol. 27, pp. 198-204, May 1955.

17. L. E. Getgen, "Application of Matrix Algebra to Circuit Design, " Electro-Technology, pp. 7079, Feb. 1963 .
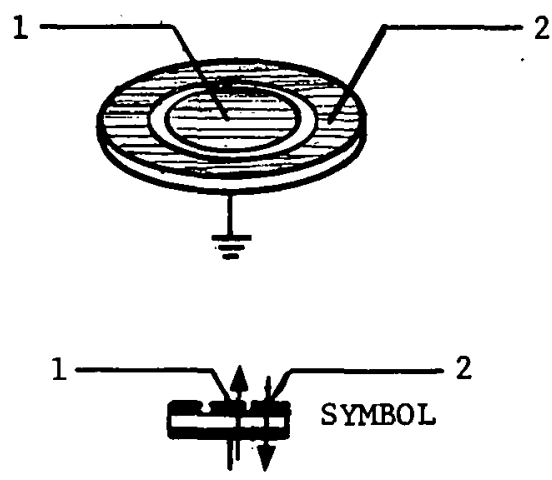

FIGURE 1B

Fig. 1-Electrode configurations and schematic symbols for two-port bar and disk feedback structures. (a) Arrows indicate directions of polarization of the ceramic.

(b) 

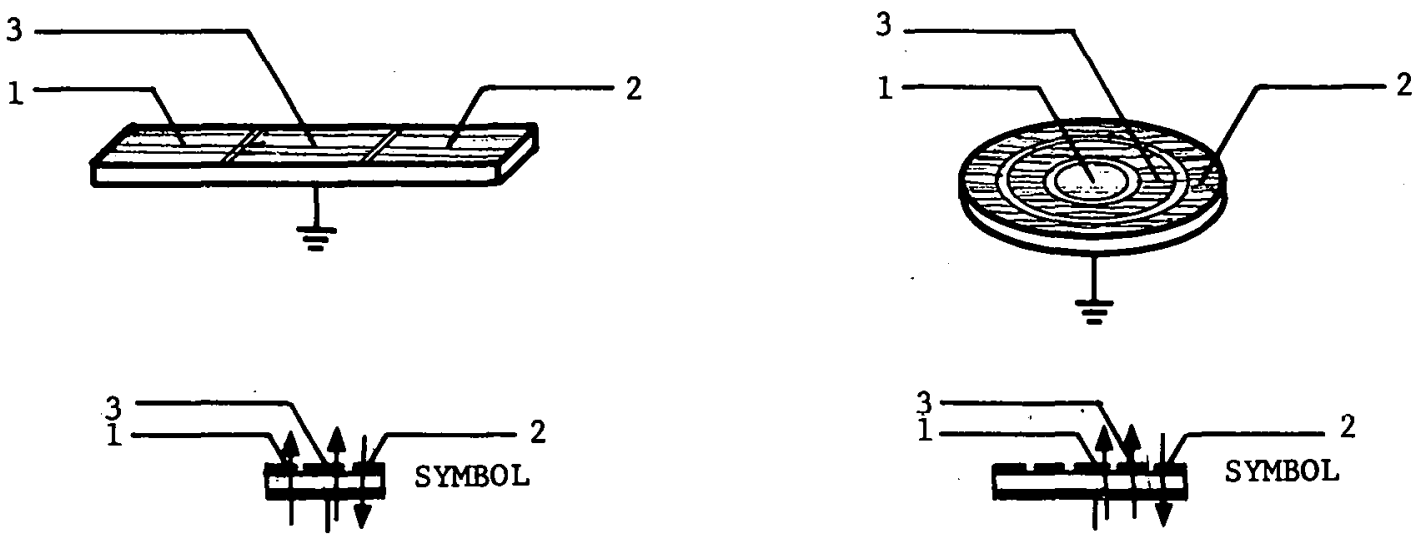

FIGURE 2A

FIGURE 2B

Fig. 2-Electrode contigurations and schematic symbols for three-port bar and disk feedback structures. Arrows indicate directions of polarization of the ceramic.

(a)

(b)

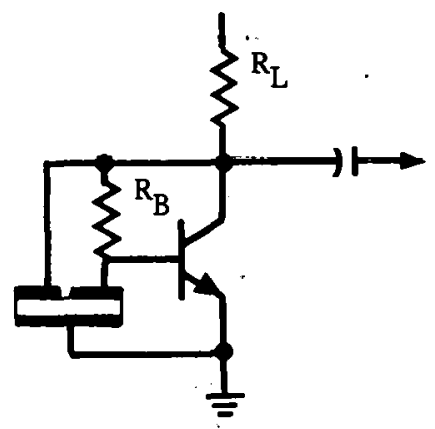

FIGURE $3 A$

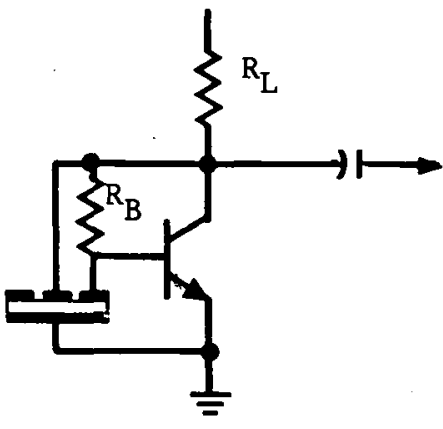

FIGURE 3B

Fig. 3-Schematic diagrams of fixed frequency oscillators using three-port feedback networks.

(a)

(b)

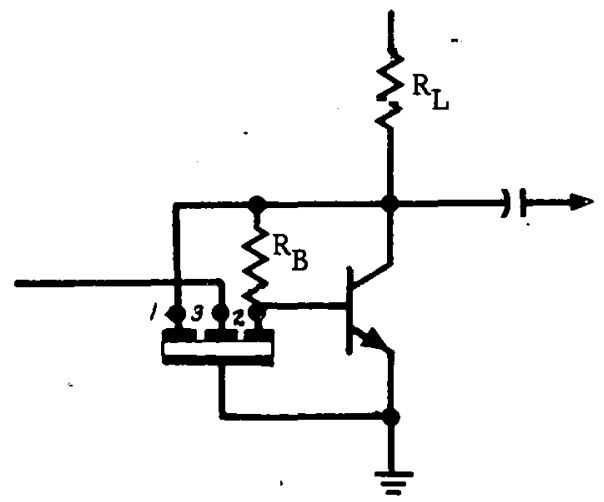

FIGURE $4 \mathrm{~A}$

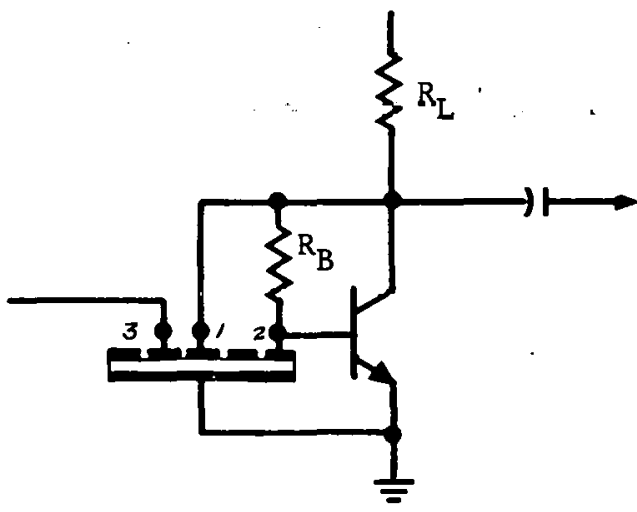

FIGURE 4B

Fig. 4-Schematic diagrams of variable frequency oscillators using three-port feedback networks. 

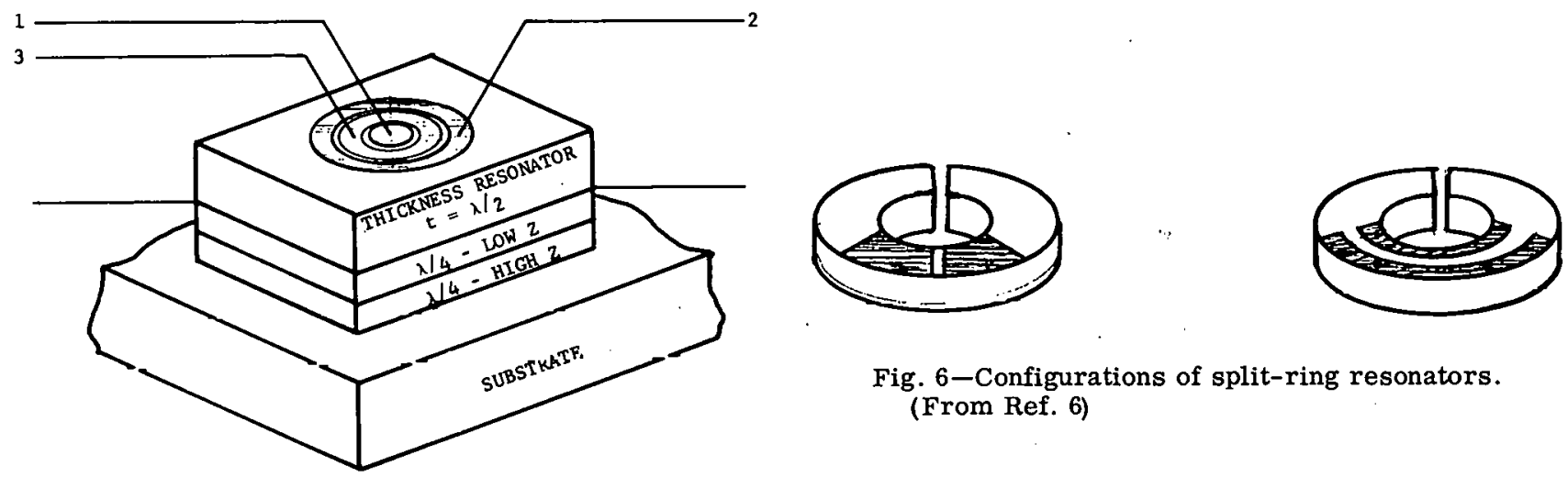

Fig. 6-Configurations of split-ring resonators. (From Ref. 6)

Fig. 5-Solidly mounted thickness resonator using $\lambda / 4$ interlayers. (From Ref. 5 )

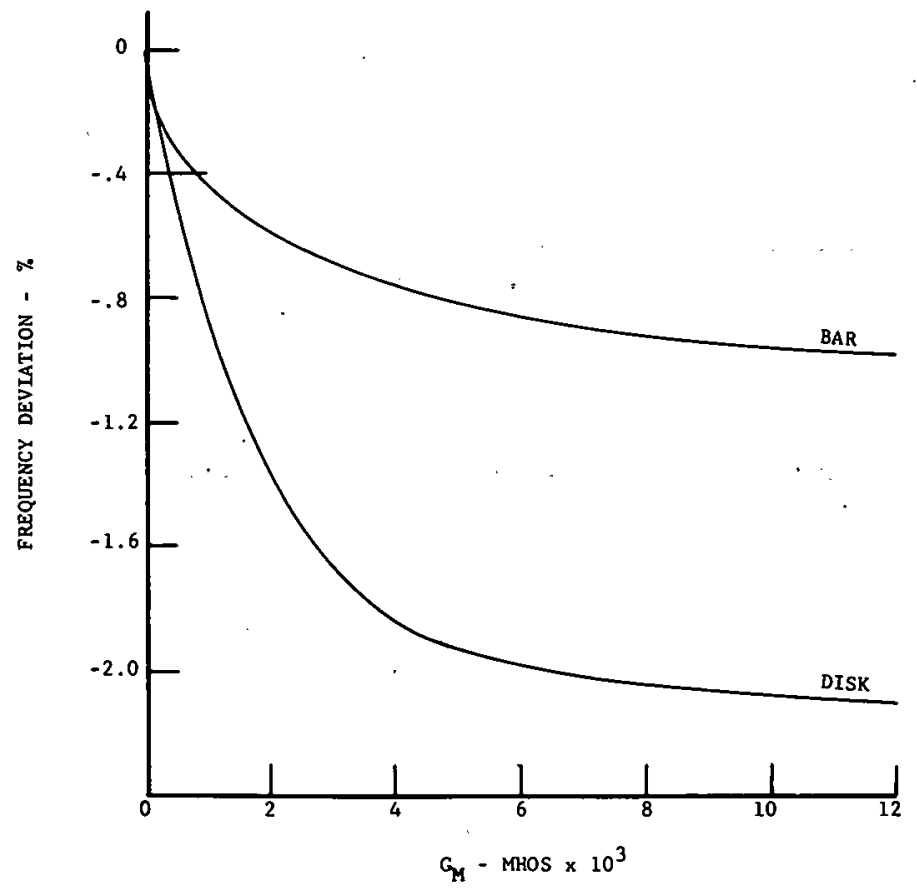

Fig. 7-Oscillator frequency deviation as a function of resistive termination of Port 3 for both bar and disk feedback networks. 


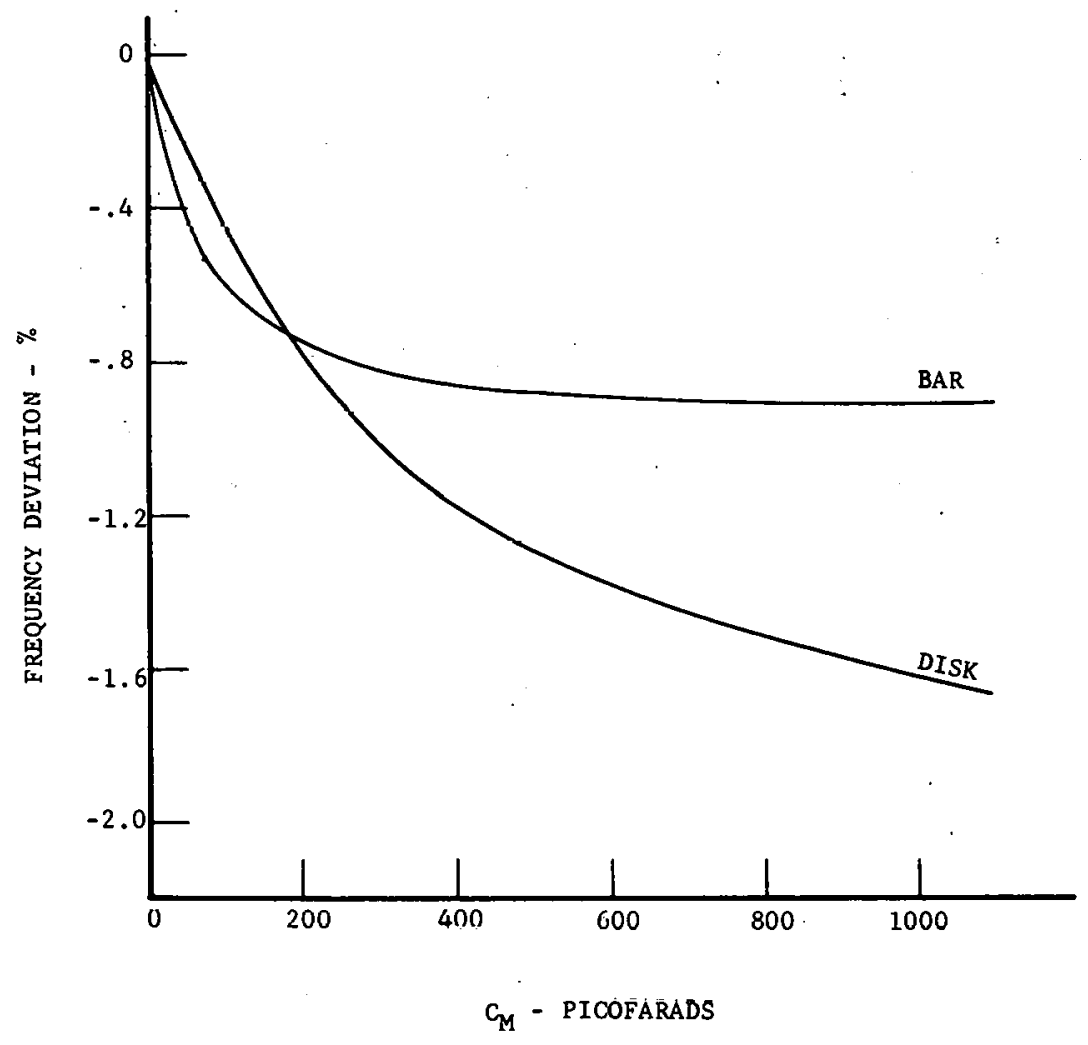

Fig. 8-Oscillator frequency deviation as a function of capacitive termination of Porl 3 fui both bar and ulsk leéuliak nelwurlus. 


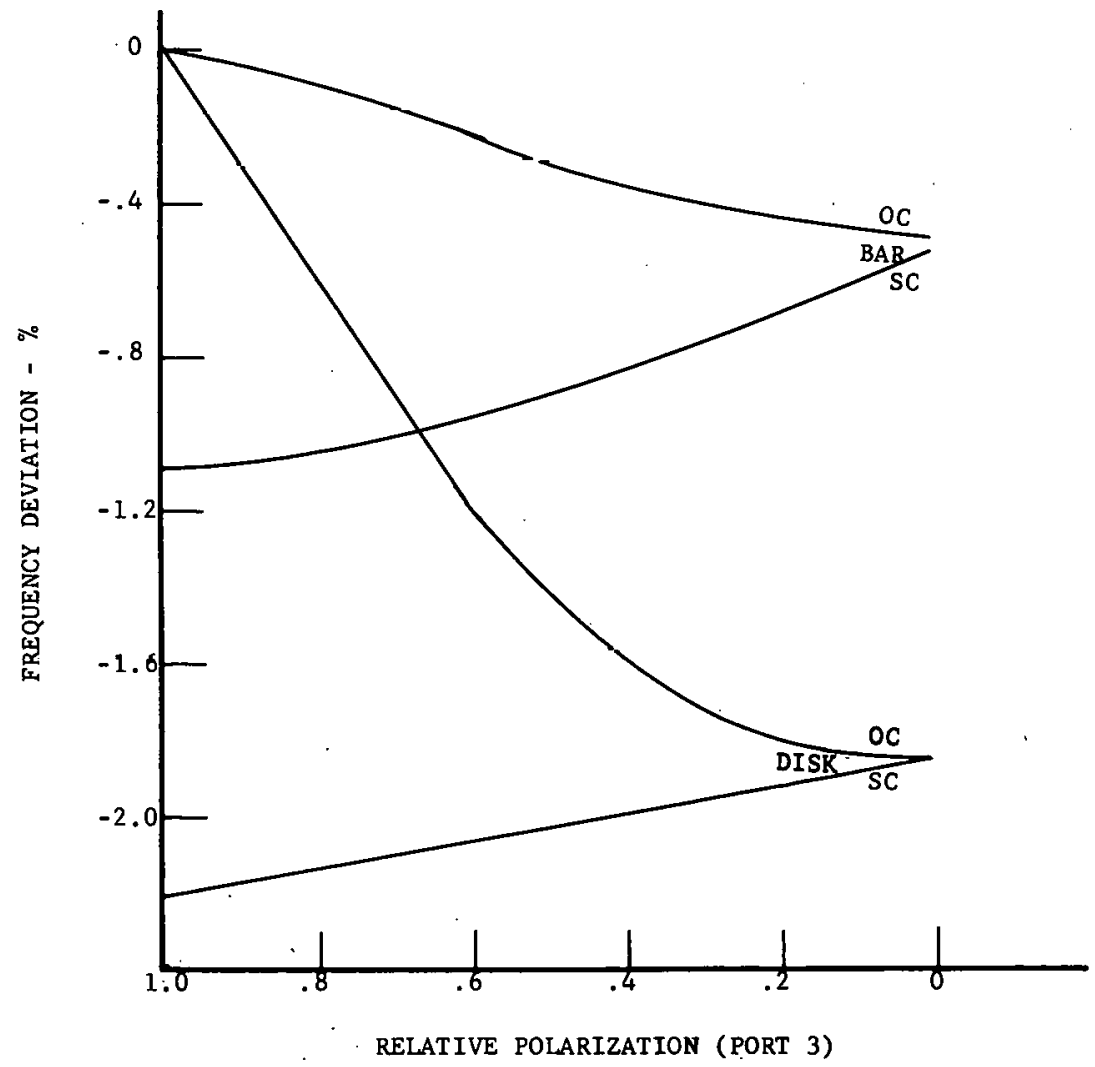

Fig. 9-Oscillator frequency deviation as a function of polarization at Port 3 for both bar and disk resonators. 


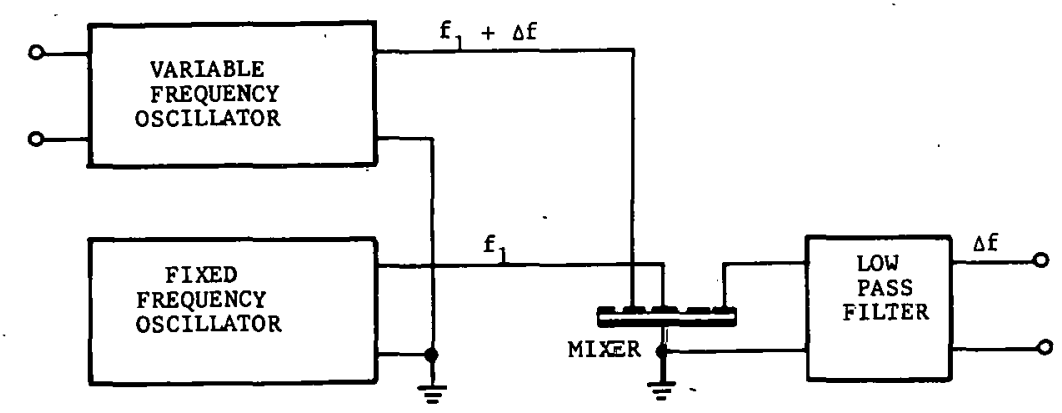

Fig. 10-Heterodyne or down-converter s;stem for effectively increasing

percentage frequency deviation.

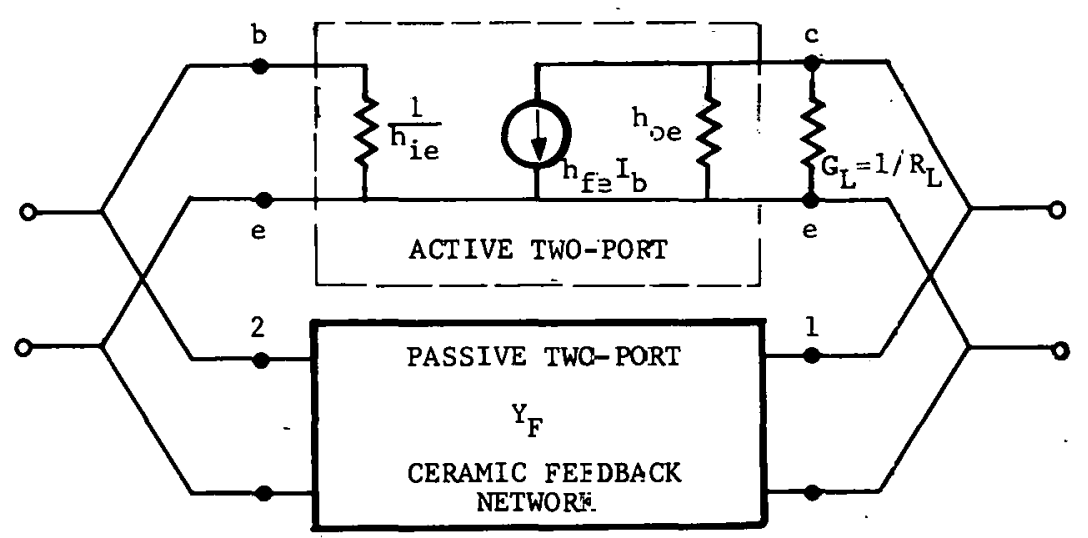

Fig. 11-Two-port equivalent circuil representation of oscillator.

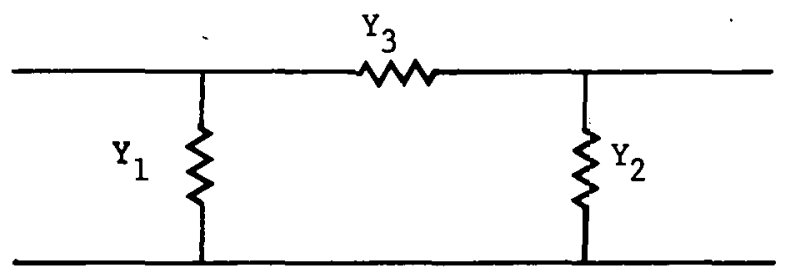

Fig. 12-The general pi network equivalent circuit of the feedback network.

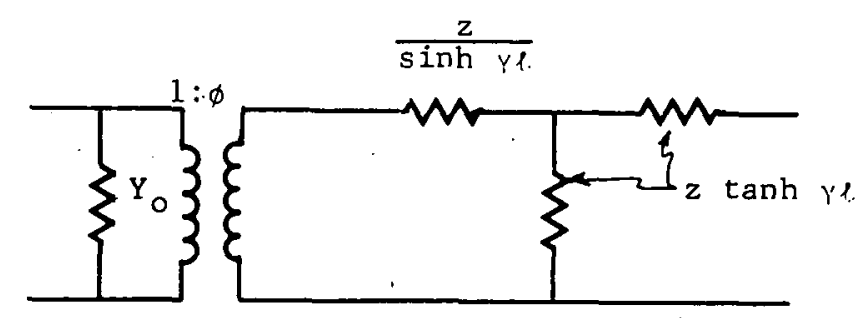

Fig. 13-Distributed parameter equivalent circui: of a bar resonator with one end free and one end clamped. 

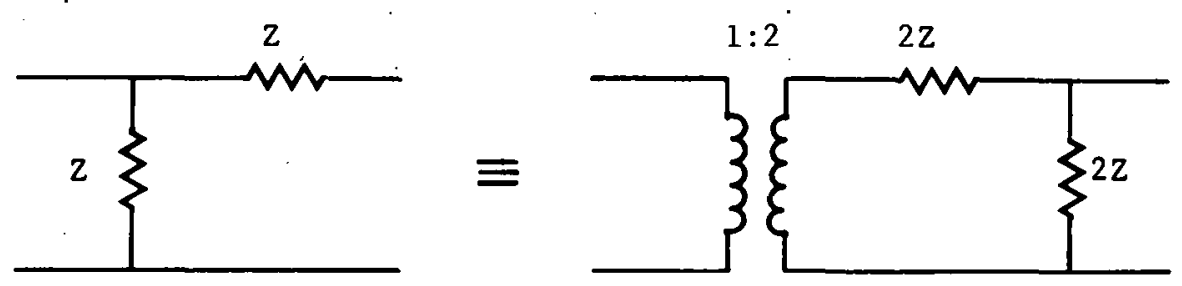

Fig. 14-Norton transformation.

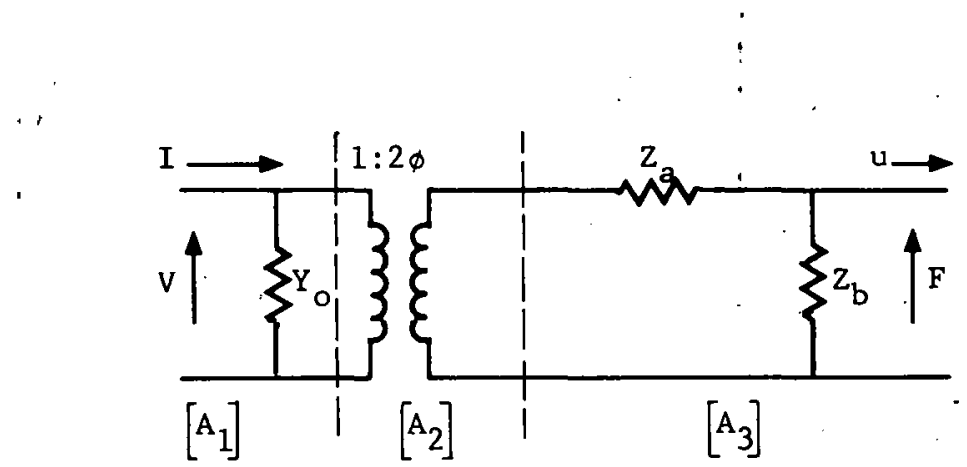

Fig. 15-Transformed circuit corresponding Figure 13.

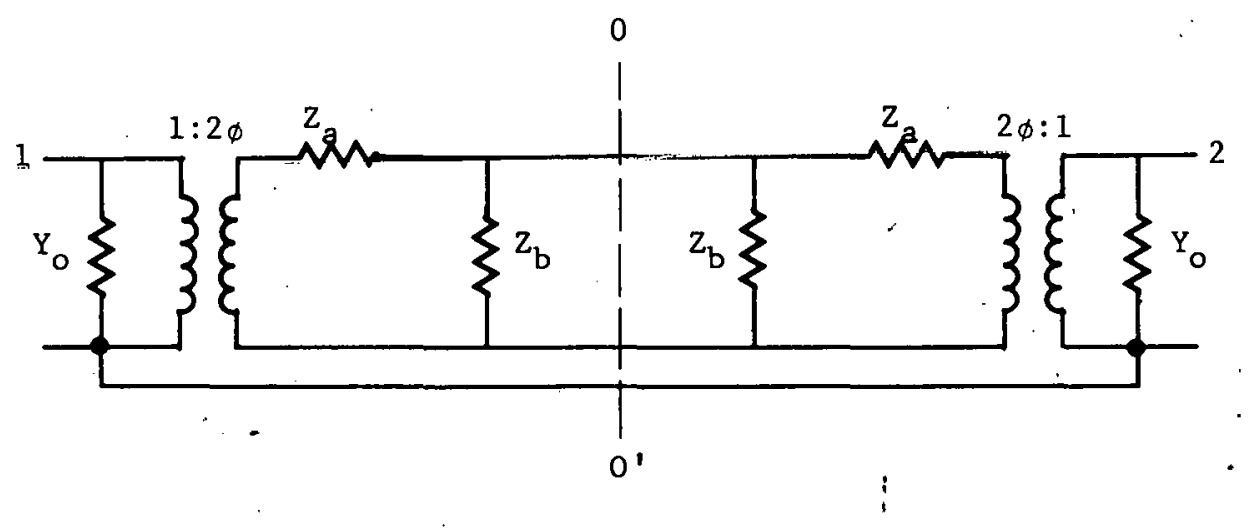

Fig. 16-Distributed parameter equivalent circuit of the bar of Figure 1A.

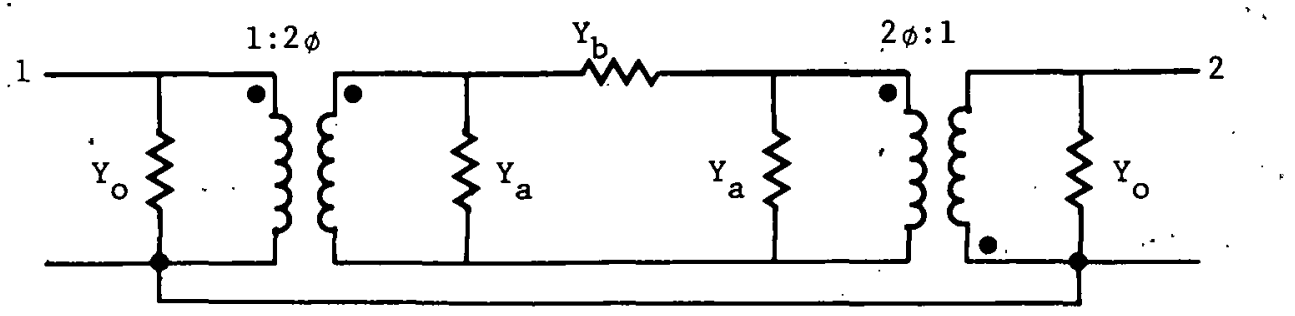

Fig. 17-Pi network distributed parameter equivalent circuit of the feedback structure of Figure 1A. Ceramic polarization is indicated by the sense of the ideal transformer windings. 


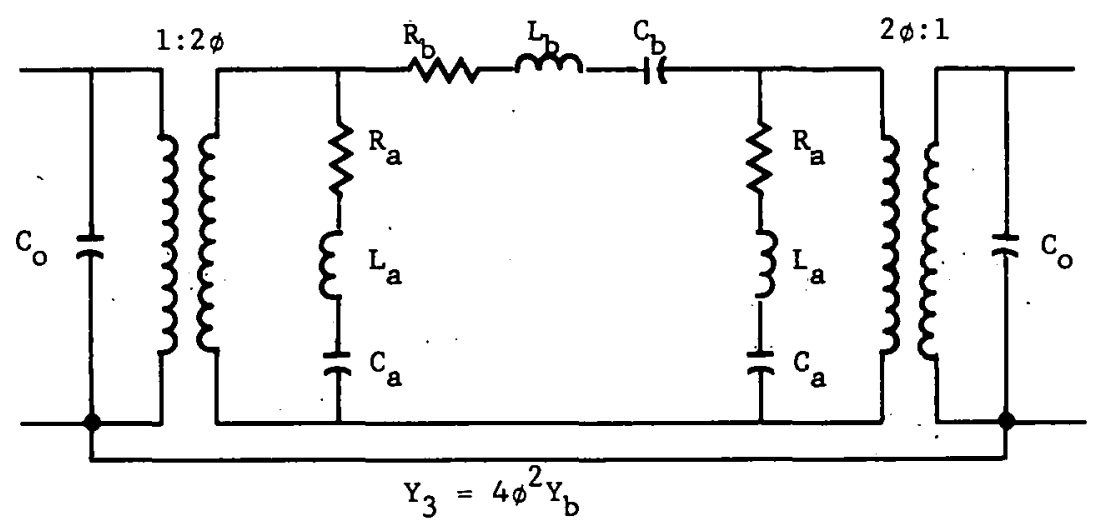

Fig. 18-Pi network lumped parameter equivalent circuit of the feedback structure of Figure $1 \mathrm{~A}$

\&

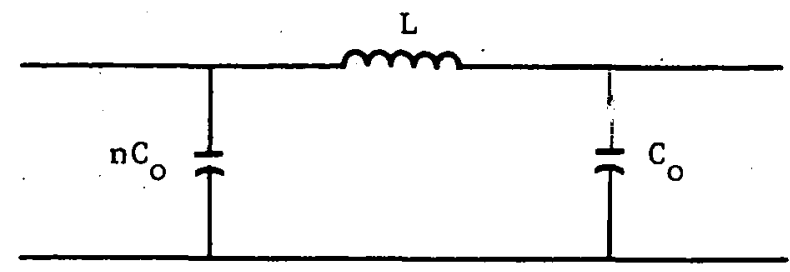

Fig. 19-Simplified lumped parcmeter equivalent circuit of feedback network at the oscillator frequency.

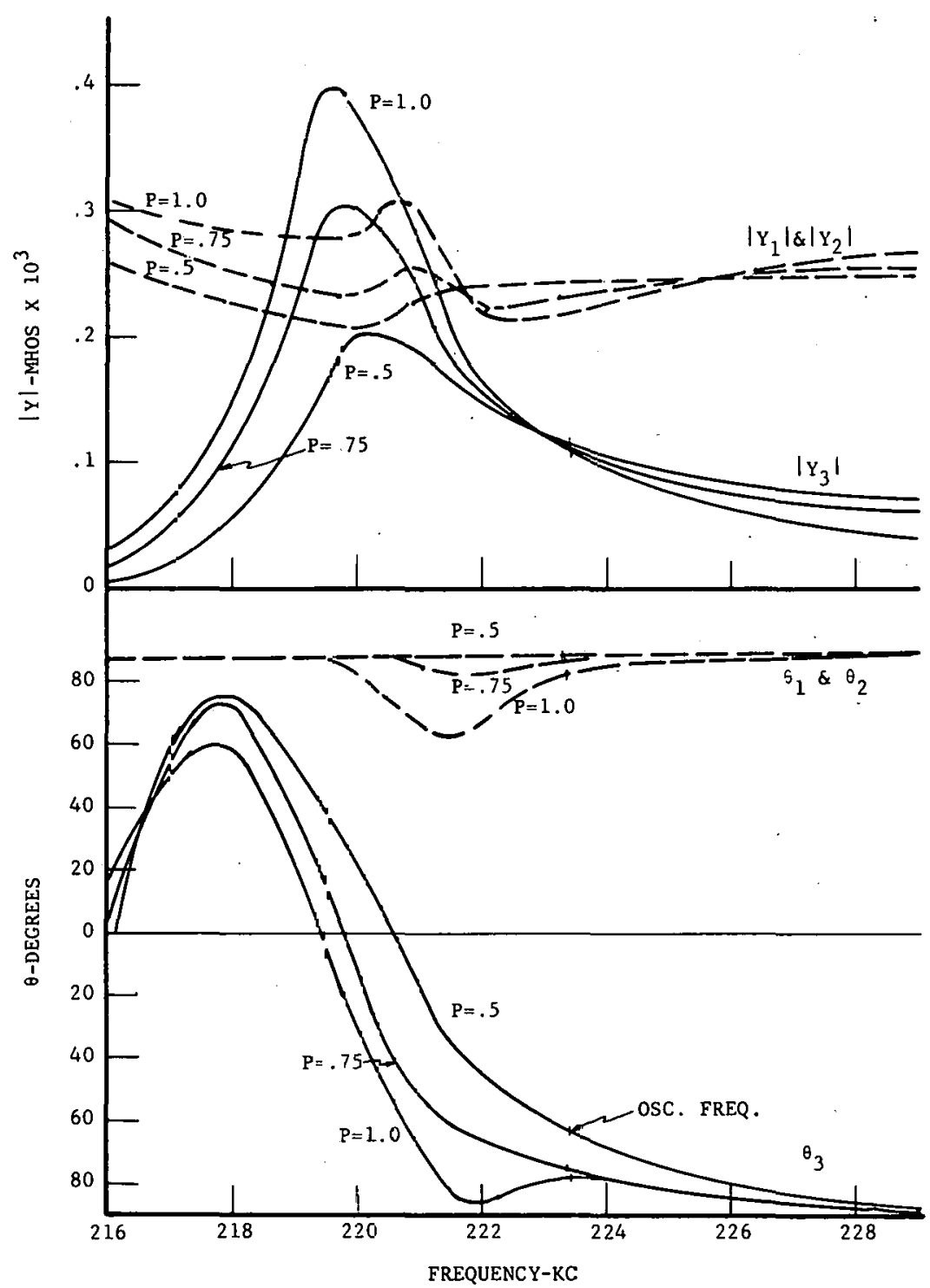

Fig. $20-Y_{1}, Y_{2}, Y_{3}$ as functions of frequency with polarization at imput port as a parameter for the feedback netw'ork of Figure 1A. 


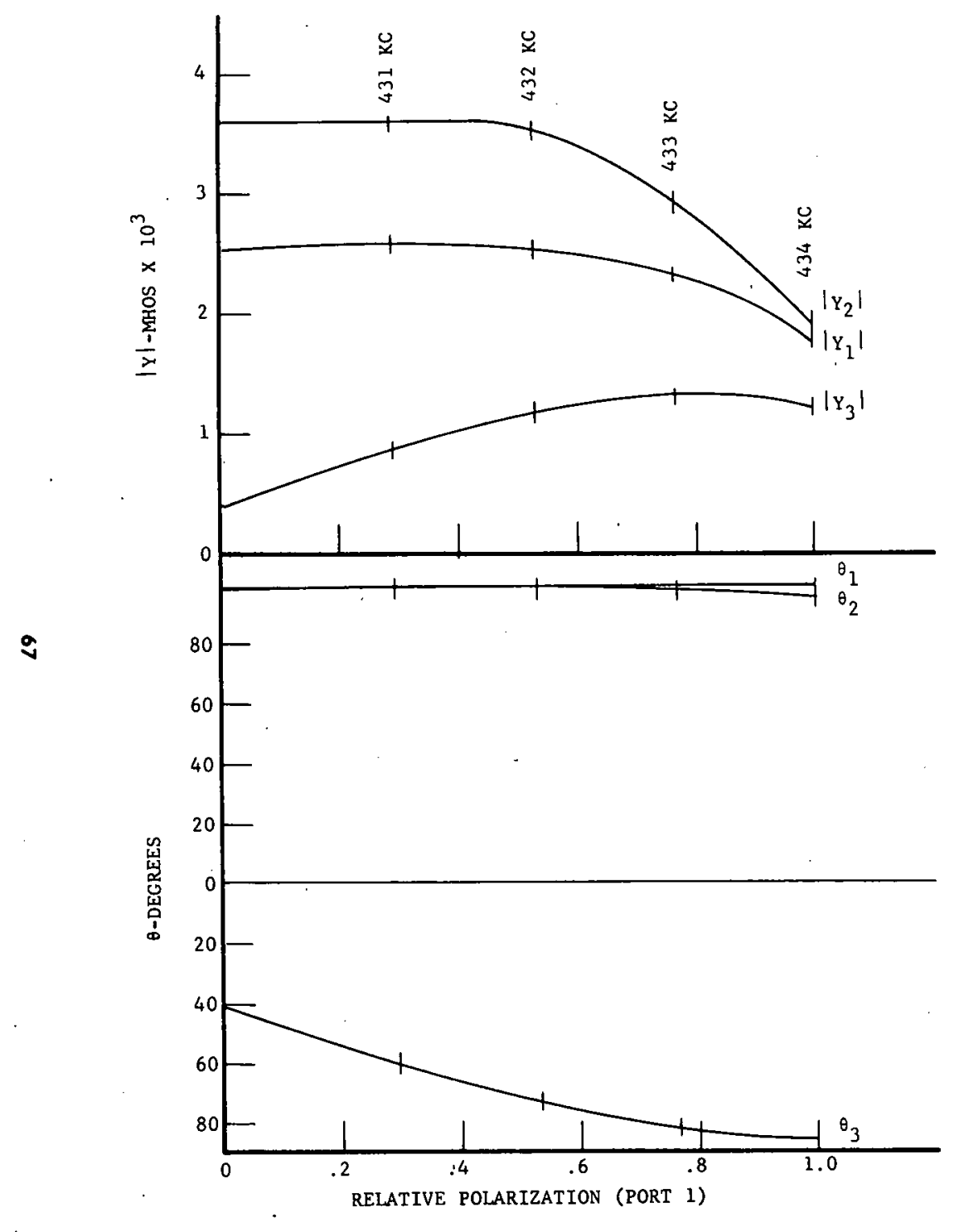

Fig. 21- $Y_{1}, Y_{2}$, and $Y_{3}$ as functions of polarization at imput port of the feedback network of Figure $1 \mathrm{~B}$ (measured at oscillator frequency).

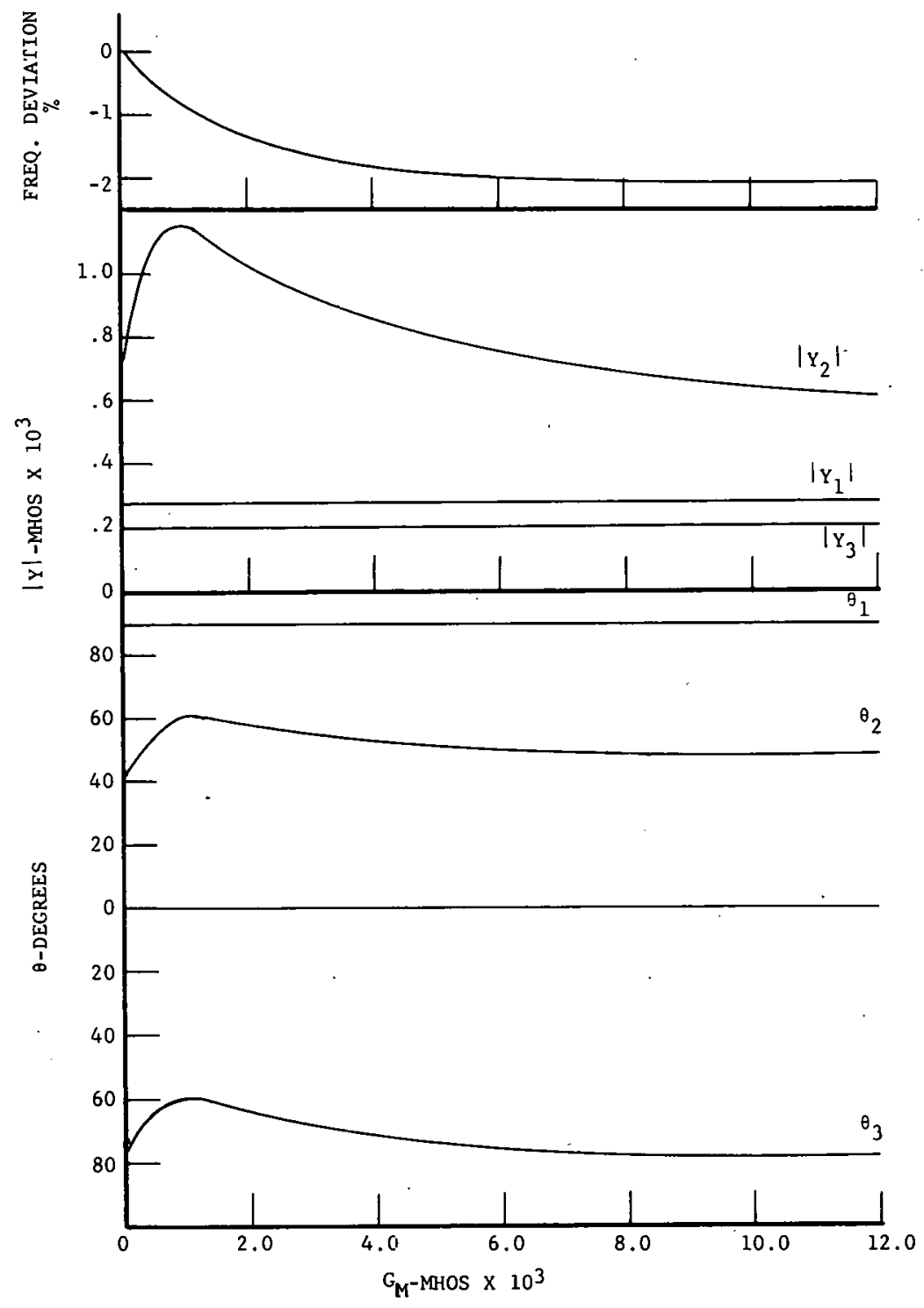

Fig. 22- $\mathrm{Y}_{1}, \mathrm{Y}_{2}$, and $\mathrm{Y}_{3}$ as functions of conductive termination $\mathrm{G}_{\mathrm{M}}$ at Port 3 of the feedback network of Figure $2 B$ (measured at the oscillator frequency) 


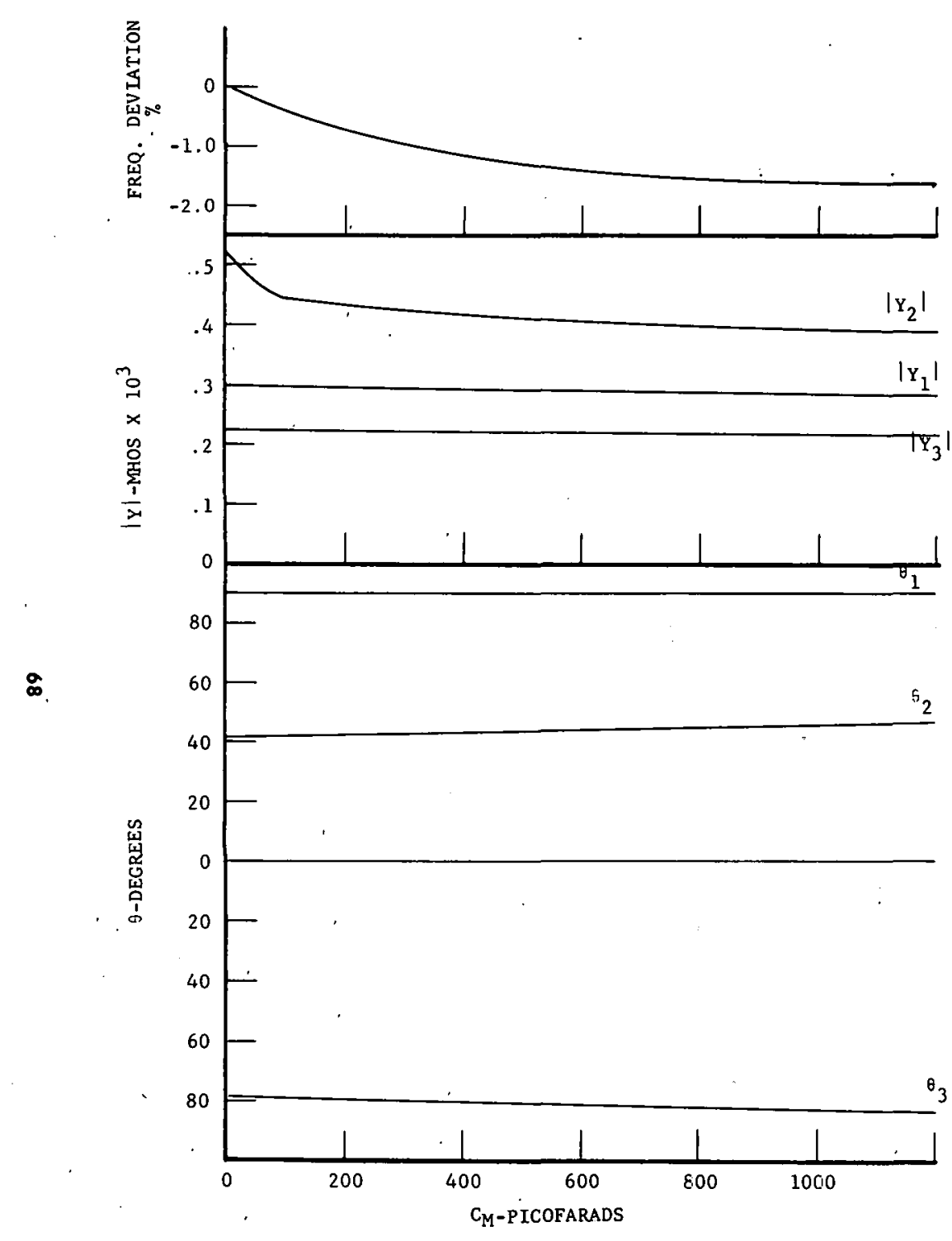

Fig. 23- $Y_{1}, Y_{2}$, and $Y_{3}$ as functions of capacitive termination $\mathrm{C}_{\mathrm{M}}$ at Port 3 of the feedback network of Figure 2B (measured at the oscillato: frequency).

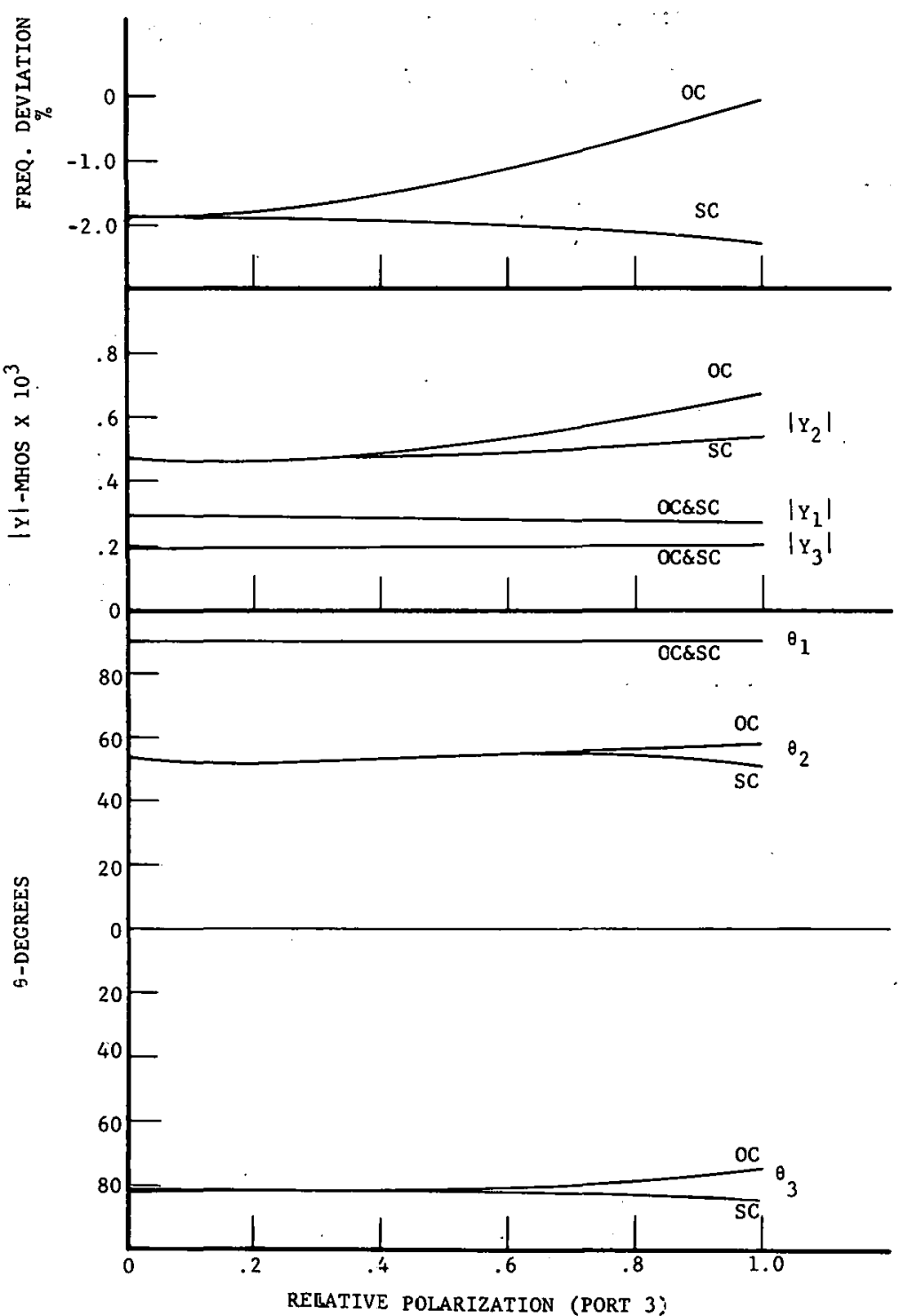

Fig. 24- $Y_{1}, Y_{2}$, and $Y_{3}$ as functions of polarization at modulation Fort 3 of the feedback network of Figure 2B (mecsured at the oscillator frequency for open-circuit and short-circuit termination at Part 3). 